\title{
Volume 104, Issue 1, January 2022
}

\section{Kimon P. Valavanis ${ }^{1}$}

Published online: 1 January 2022

(c) The Author(s), under exclusive licence to Springer Nature B.V. 2021

\section{Dear Colleagues:}

At first, I would like to wish you a happy and prosperous new year with health, happiness, and prosperity. Granted, the future is still unknown when it comes to the COVID-19 pandemic and its mutations, c'est la vie, but we cannot put everything on hold because of it. We continue with our lives, and we will adjust as needed.

This new year finds JINT as strong as never before. Paper submissions exceeded 1,000 in 2021 - I will report on the exact number in the February editorial; the transition to CAP is now as smooth as it can be; accepted papers are actually published as soon as the final files are received; all papers are processed and assigned to the handling editors within 24-48 $\mathrm{h}$ after they are received by the EIC. There is regular correspondence between the EIC, handling editors, and assigned reviewers, and 'reminders' are sent to meet paper review deadlines. The Springer team and the EIC work in unison to make sure that we provide you with the service you deserve. Overall, we believe we have managed to streamline the paper review cycle and to reduce the submission to first decision time. We will continue this path and fine tune the process even more.
The main objectives during the 2022 year are clear but challenging: work harder to make JINT better and improve its ranking; publish top quality papers; consider Topical Collection issues (special issues) on topics of major importance and interest to the readers. Moreover, we also plan on refreshing the editorial board with new members. Last, but not least, we will finalize the JINT 'new look' and 'new cover' to be in line with the current state-of-the-art in autonomy, intelligence, robotics, and automation.

We welcome your feedback and comments, recommendations and suggestions. We look forward to a strong year.

Enjoy the issue.

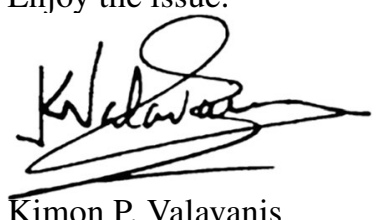

Editor-in-Chief

Publisher's Note Springer Nature remains neutral with regard to jurisdictional claims in published maps and institutional affiliations.
Kimon P. Valavanis

Kimon.Valavanis@du.edu

1 D. F. Ritchie School of Engineering and Computer Science, University of Denver, Denver, CO 80208, USA 